\title{
Construct Validity of a Serious Game for Laparoscopic Skills Training: Validation Study
}

Wouter IJgosse, MD; Harry van Goor, MD, PhD; Camiel Rosman, MD, PhD; Jan-Maarten Luursema, PhD

Department of Surgery, Radboud University Medical Center, Nijmegen, Netherlands

Corresponding Author:

Wouter IJgosse, MD

Department of Surgery

Radboud University Medical Center

Geert Grooteplein Zuid 10

Nijmegen, 6525 GA

Netherlands

Phone: 31243617612

Email: Wouter.IJgosse@ radboudumc.nl

\section{Abstract}

Background: Surgical residents underutilize opportunities for traditional laparoscopic simulation training. Serious gaming may increase residents' motivation to practice laparoscopic skills. However, little is known about the effectiveness of serious gaming for laparoscopic skills training.

Objective: The aim of this study was to establish construct validity for the laparoscopic serious game Underground.

Methods: All study participants completed 2 levels of Underground. Performance for 2 novel variables (time and error) was compared between novices $(n=65$, prior experience $<10$ laparoscopic procedures), intermediates $(n=26$, prior experience $10-100$ laparoscopic procedures), and experts $(n=20$, prior experience $>100$ laparoscopic procedures) using analysis of covariance. We corrected for gender and video game experience.

Results: Controlling for gender and video game experience, the effects of prior laparoscopic experience on the time variable differed significantly $\left(F_{2,106}=4.77, P=.01\right)$. Both experts and intermediates outperformed novices in terms of task completion speed; experts did not outperform intermediates. A similar trend was seen for the rate of gameplay errors. Both gender $\left(F_{1,106}=14.42\right.$, $P<.001$ in favor of men) and prior video game experience $\left(F_{1,106}=5.20, P=.03\right.$ in favor of experienced gamers $)$ modulated the time variable.

Conclusions: We established construct validity for the laparoscopic serious game Underground. Serious gaming may aid laparoscopic skills development. Previous gaming experience and gender also influenced Underground performance. The in-game performance metrics were not suitable for statistical evaluation. To unlock the full potential of serious gaming for training, a more formal approach to performance metric development is needed.

(JMIR Serious Games 2020;8(2):e17222) doi: $\underline{10.2196 / 17222}$

\section{KEYWORDS}

laparoscopy; surgery; training; education; serious game; resident training; skills development; psychomotor skills; simulation center

\section{Introduction}

Simulation has been proven to be effective for laparoscopic skills training [1]. However, due to scheduling constraints and motivational issues, simulation training opportunities for residents remain underutilized [2,3]. Consequently, the burden of the surgical learning curve continues to fall on the patient [4-6]. Serious gaming can address these issues by providing a training modality that is fun, challenging, easy to implement, and inexpensive compared to current laparoscopic simulators [7]. Serious gaming refers to the application or adaptation of computer games for nonrecreational purposes, such as learning, training, or therapy [8]. This can lead to "stealth learning" [9], where the trainee is enjoying the training so much that they fail to notice improvements in key education outcomes [10,11]. Due to these attributes, serious gaming is a good candidate to alleviate motivational issues. Serious games are also easy to 
implement in a home environment, which can address the issue of scheduling constraints at work.

Serious gaming for psychomotor skills training is a new concept in surgery; however, it has been demonstrated to be successful in several other fields, including rehabilitation clinics and the aviation industry [12-15]. In these games, movements necessary to engage in gameplay are modeled on relevant motor tasks as they occur in reality in order to impart the requisite motor skills. This approach was adopted for laparoscopic skills training by ten Cate Hoedemaker and Grendel Games [16], who developed the serious game Underground for the Nintendo Wii U platform. In this game, medical content is replaced by a narrative that focuses on saving robots from a system of abandoned mineshafts. The psychomotor skills necessary to complete in-game tasks are closely modeled on laparoscopic movements and are performed using gaming controllers that resemble laparoscopic hardware. If effective, serious gaming can contribute to laparoscopic skills development by increasing training volume in the guise of a leisure activity.

In a previous study, we established concurrent validity by demonstrating skill transfer between Underground and the LapSim virtual reality trainer $[17,18]$. Limited evidence of construct validity has been offered by Jalink et al [18], who compared the performance of laparoscopic experts and internists playing Underground. However, this study compared groups who may differ in their innate abilities to perform psychomotor tasks [19]; also, it used a prototype of the game instead of the final product.

To assess the potential of Underground as a surgical training tool, validity criteria must be met, including construct validity [20]. Construct validity is the degree to which a test truly measures what it intends to measure; in this instance, it refers to the degree to which a serious game measures differences in the skills it is designed to evaluate. Therefore, the aim of this study was to establish construct validity for the laparoscopic serious game Underground. We compared the gaming performance of surgical novices, surgical house officers, surgical residents, and laparoscopic surgeons based on their self-reported laparoscopic experience. We hypothesized that more real-world laparoscopic experience would translate to better Underground gaming performance.

\section{Methods}

\section{Participants}

Study participants were selected from 4 different groups: fourth year medical students preparing for their surgical internships (surgical novices), surgical house officers, surgical residents, and staff laparoscopic surgeons from the departments of Colorectal and Hepatobiliary Surgery, Urology, and Gynecology. All participants were recruited at the Radboud University Medical Center, Nijmegen, the Netherlands. No IRB approval was needed for this study under Dutch law [21].

Performance data for the surgical novices were collected during a mandatory basic laparoscopic skills training course. The participants were informed about our study, and each participant voluntarily signed an informed consent form to allow us to use their anonymized performance data for research purposes. Participants were made aware that declining to sign this form did not impact their course participation or the assessment of their internship. Surgical house officers, surgical residents, and staff surgeons were recruited via emails, posters in the hospital, and in-person interactions. Participation was voluntary and did not result in compensation. All subjects were divided into 3 groups based on their self-reported laparoscopic experience: novices, who had performed fewer than 10 laparoscopic procedures (typically surgical novices and surgical house officers), intermediates, who had performed between 10 and 100 laparoscopic procedures (typically surgical residents), and experts, who had performed more than 100 laparoscopic procedures (typically laparoscopic surgeons) [22].

\section{Study Design}

An instructor was present throughout the session to observe the participants, provide instructions, and troubleshoot the game when necessary. After completing the informed consent form, the participants played the first 2 levels of the laparoscopic serious game Underground to familiarize themselves with the software and hardware of the system. Next, they played through the fourth and fifth levels of Underground while being timed and scored for error by the instructor. The fourth and fifth levels were selected as the basis of the assessment because of the more challenging nature of these levels, in which all basic laparoscopic skills were tested (eg, inverted movements, hand-eye coordination, depth perception, and ambidexterity). Participants subsequently completed a demographic questionnaire that included sections on prior laparoscopic experience and prior video game experience. Each complete session took an average of 30 minutes per individual.

Gaming sessions took place in a quiet working space located within the Department of Surgery (Figure 1). Fluorescent lights and sources of infrared light were turned off in the gaming area, as they are known to interfere with the Nintendo Wii-U system used in this study [23]. 
Figure 1. Laparoscopic interface of the serious game Underground.

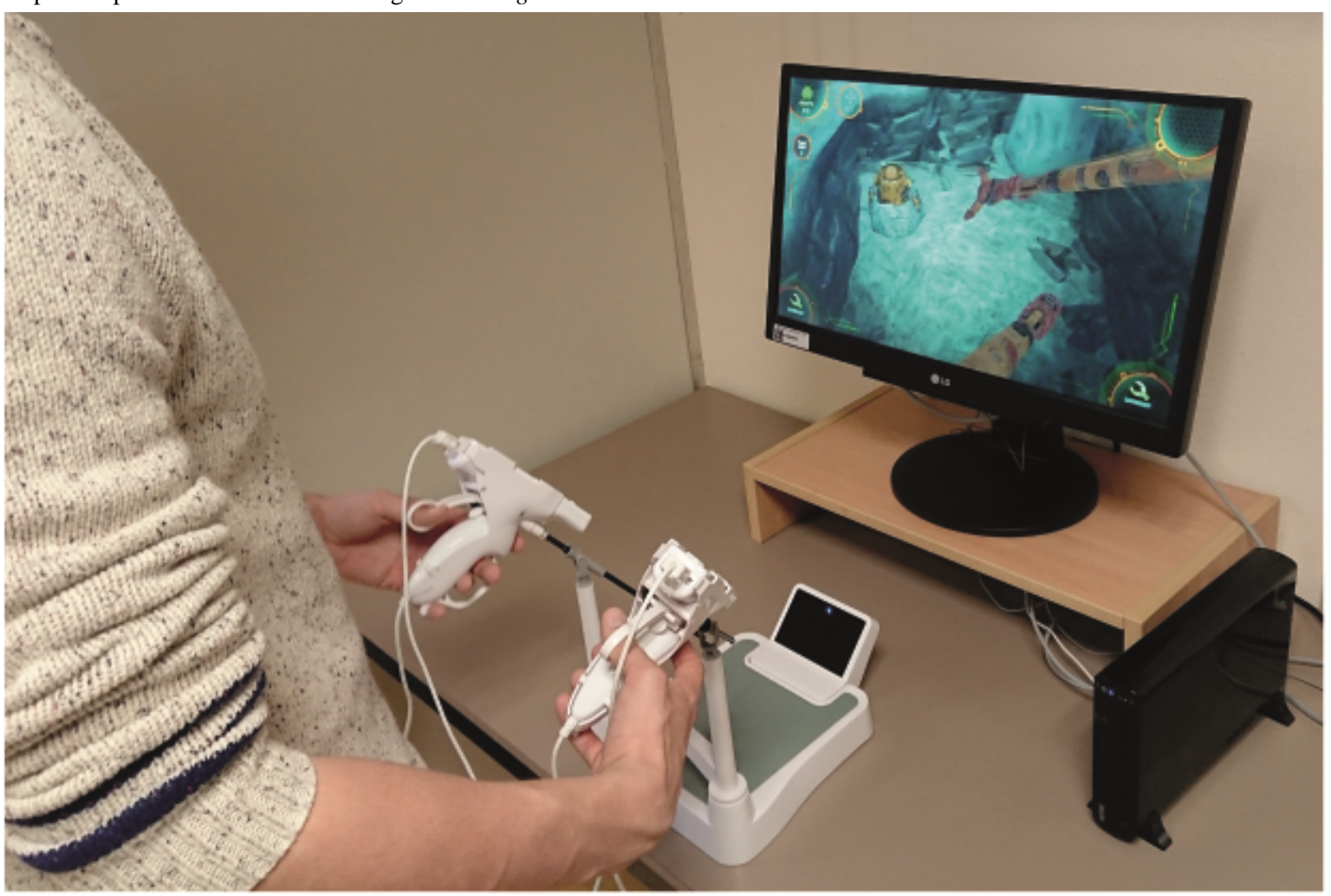

\section{Apparatus}

We utilized Underground Version 1.1 with a dedicated laparoscopic interface for this study (Grendel Games). The serious game was played on a Nintendo Wii U video gaming system connected to a 21 " HD LCD screen (LG Corporation). The game instrument sensitivity was set at maximum [24,25].

\section{Data Preparation}

Currently, Underground contains no formal embedded performance metrics relevant to laparoscopic skills training. Thus, in order to analyze game performance as it relates to surgical activities, we created 2 measured variables: time and error. Time was the measurement of how quickly the player was able to complete all game tasks; it was defined as the elapsed time between the start and finish of each level as measured with a stopwatch. The total play times for each level were summed to generate the final time measurement. Error was defined as the total sum of occurrences of 3 key player mistakes: orb drops, roadblocks, and robot deaths.

Video game experience was measured by asking all participants to estimate their average number of weekly gaming hours across several age-bands (1-6 years, 7-12 years, 13-18 years, 19-25 years, 26-45 years, and $\geq 46$ years) [26]. We then calculated each participant's total prior lifetime gaming experience by multiplying the average number of gaming hours per week by the number of weeks in the selected age bands. Since the resulting total gaming hours variable was not normally distributed, we ranked these data to render them suitable for non-parametric statistical analyses.

\section{Data Analysis}

Sample size was calculated using $\alpha=.05$, a power of .95 , a large effect size of 0.40 , and 3 groups $[18,27]$. This resulted in a desired total sample size of 102 . Normality for the variable time was confirmed using the Shapiro-Wilk test, allowing for parametric testing. We performed analysis of covariance (ANCOVA) to assess the effects of laparoscopic experience on the "time" performance variable, controlling for prior video game experience and gender. After performing ANCOVA on all groups together, planned contrasts were used to assess differences in performance for paired groups [28]. The incidence of error was not normally distributed for the novice or expert groups, as assessed by the Shapiro-Wilk test. We therefore used Mann-Whitney U tests to compare the number of errors between groups. $\alpha$ was set at .05. Power analyses were conducted in G*Power version 3.1.9.2. Statistical analyses were performed with SPSS version 25.0 (IBM Corporation).

\section{Results}

\section{Participants}

A total of 120 participants were enrolled in this study. Data for 9 participants ( 2 surgical novices, 4 surgical residents, 1 surgical house officer, and 2 laparoscopic surgeons) were excluded from the analyses because these participants were unable to complete the study due to hardware failure or urgent patient care activities. Data for 65 novice, 26 intermediate, and 20 expert participants were used. Gender proportions varied between experience groups (Table 1). Men had more video game experience than women in the novice group $\left(t_{63}=4.94, P<.001\right)$ and intermediate group $\left(t_{24}=3.00, P=.01\right)$. No gender-based difference for video game experience was found in the expert group. 
Table 1. Demographics of the participant groups.

\begin{tabular}{|c|c|c|c|}
\hline Characteristic & Novice $(\mathrm{n}=65)$ & Intermediate $(n=26)$ & Expert $(n=20)$ \\
\hline Age (years), mean (SD) & $24(3)$ & $31(2)$ & $44(6)$ \\
\hline Male gender, $\mathrm{n}(\%)$ & $20(31)$ & $16(62)$ & $17(85)$ \\
\hline Right-hand dominance, n (\%) & $57(87)$ & $23(89)$ & $20(100)$ \\
\hline Video game experience, mean rank & 56 & 60 & 50 \\
\hline \multicolumn{4}{|l|}{ Professional status, n (\%) } \\
\hline Surgical novice & $54(83)$ & $\mathrm{N} / \mathrm{A}^{\mathrm{a}}$ & N/A \\
\hline Surgical house officer & $11(17)$ & N/A & N/A \\
\hline Surgical resident & N/A & $26(100)$ & N/A \\
\hline Laparoscopic surgeon & N/A & N/A & $20(100)$ \\
\hline \multicolumn{4}{|l|}{ Department, n (\%) } \\
\hline No department (surgical novice) & $54(83)$ & N/A & N/A \\
\hline Surgery & $11(17)$ & $18(69)$ & $14(70)$ \\
\hline Urology & N/A & $3(12)$ & $2(10)$ \\
\hline Gynecology & N/A & $5(19)$ & $4(20)$ \\
\hline
\end{tabular}

${ }^{\mathrm{a}}$ Not applicable.

\section{Time Performance Variable}

After controlling for gender and prior video game experience by including them as covariates in ANCOVA, the participants' game completion times differed significantly depending on their laparoscopic experience $\left(F_{2,106}=4.77, P=.01\right)$. Planned contrasts revealed that experts (mean difference -88 seconds, 95\% CI -146 to $-30, P=.002$ ) and intermediates (mean difference -43 seconds, $95 \% \mathrm{CI}-92$ to $5, P=.04$ ) performed faster than novices. Experts did not outperform intermediates (mean difference -45 seconds, $95 \%$ CI -106 to $-17, P=.08)$. The performance distribution of each group is shown in Figure 2.

Figure 2. Box plots showing the performance distribution for time between groups. The assessment time is the sum of the time scores for levels 4 and 5 of the serious game Underground.

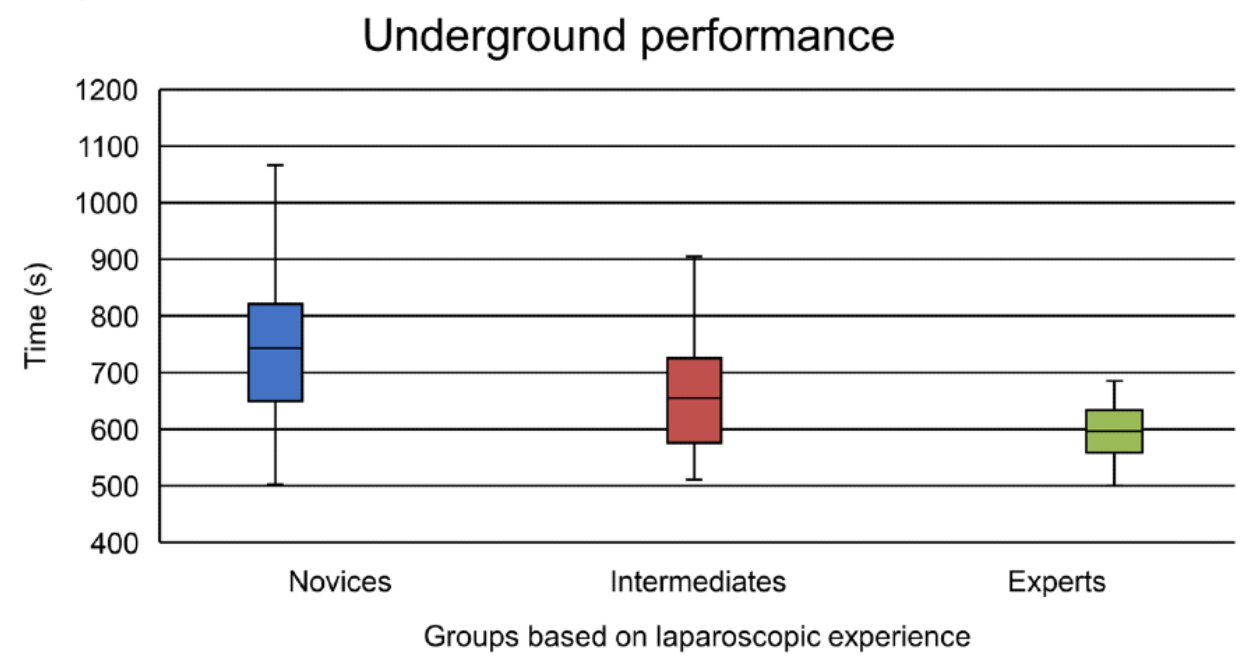

Performance for the time variable differed significantly depending on the participants' gender $\left(F_{1,106}=14.42, P<.001\right)$. This effect was caused by men outperforming women in the novice group $\left(t_{63}=-4.68, P<.001\right)$. No significant differences in performance for gender were found in the other groups.

Video game experience was also significantly related to the time performance variable $\left(F_{1,106}=5.20, P=.03\right)$. A correlation between video game experience and game completion time was observed for both novices and intermediates but not for experts. The linear trend lines for the video game experience of each group are shown in Figure 3.

We were not able to establish independence of the gender and prior video game experience variables. 
Figure 3. Linear trend lines showing the correlation between video game experience and the performance variable of time for each group.

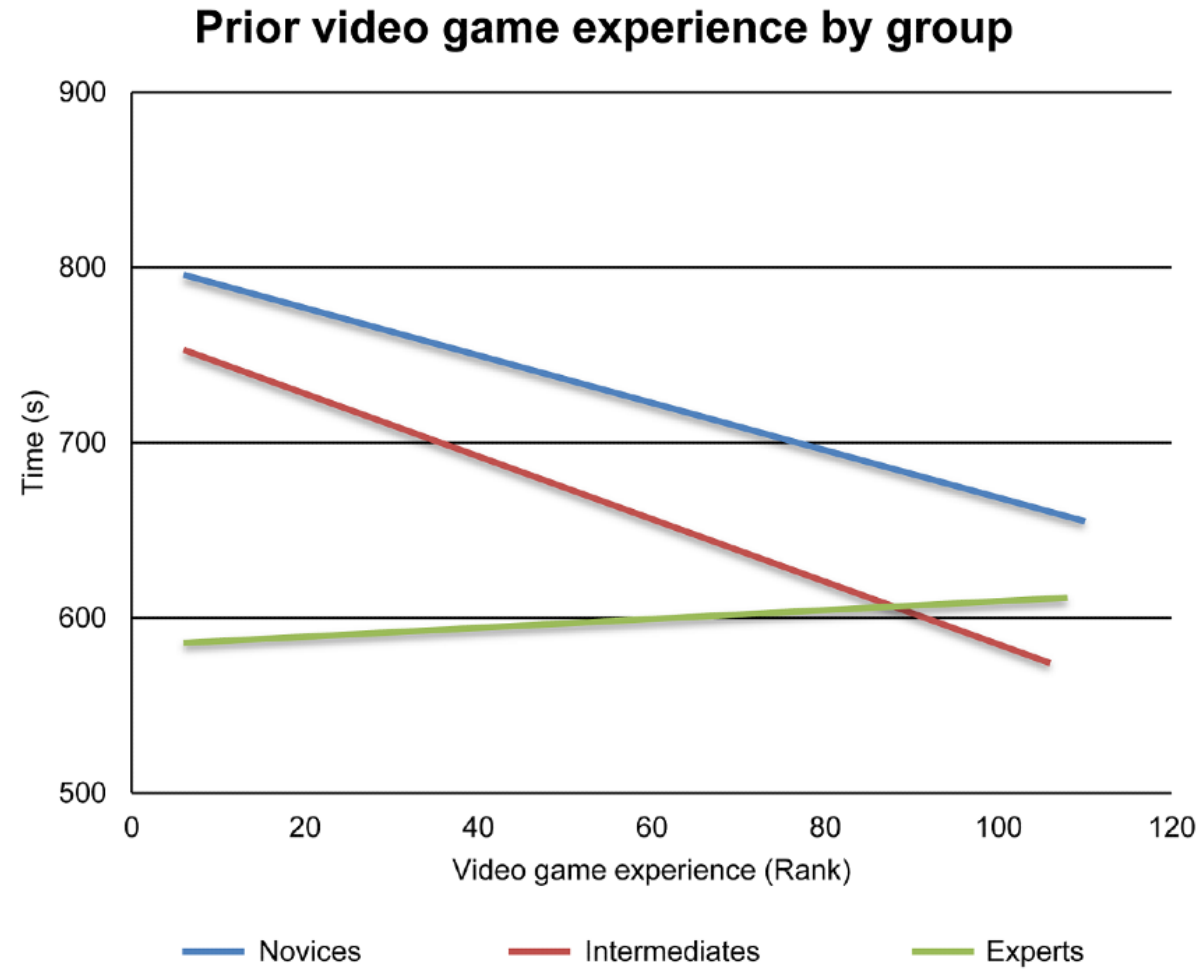

\section{The Error Performance Variable}

In all groups, the subjects made few errors, and data were only normally distributed within the intermediate group. The differences in error performance between the experience groups were qualitatively similar to the differences in time performance but did not reach statistical significance. A floor effect and a limited range of errors were observed, ranging from 0-6 (Table 2).

Table 2. Numbers of participants who made 0,1-3, and 4-6 errors in each group.

\begin{tabular}{|c|c|c|c|}
\hline \multirow[t]{2}{*}{ Errors, $\mathrm{n}$} & \multicolumn{3}{|l|}{ Group, n (\%) } \\
\hline & Novice $(\mathrm{n}=65)$ & Intermediate $(n=26)$ & Expert $(n=20)$ \\
\hline 0 & $3(5)$ & $3(12)$ & $4(20)$ \\
\hline $1-3$ & $38(58)$ & $18(69)$ & $16(80)$ \\
\hline $4-6$ & $24(37)$ & $5(19)$ & $0(0)$ \\
\hline
\end{tabular}

\section{Discussion}

\section{Principal Findings}

In this study, we demonstrated construct validity for the laparoscopic serious game Underground. The completion times for the investigated game levels differed between 2 pairs of the 3 paired groups; the novices were outperformed by both other groups, but there was no difference between the intermediates and experts. The lack of performance difference between the intermediate and expert groups is likely because Underground was developed to provide basic laparoscopic skills training, a skill level that is already mastered by intermediates and experts. After previous studies established face validity, concurrent validity, and partial construct validity, we now provide additional construct validity [16-18]. Underground is a welcome addition to the existing laparoscopic simulation landscape.

Measurement of the error variable was not sufficiently sensitive for a full statistical analysis. Since Underground was not developed with the intent to provide formal laparoscopic performance assessments, we created custom time and error variables as described in the Methods section. Although our results for the error variable did not demonstrate significance, we have included them here because there were trends toward differences in error performance between the experience groups; also, we feel it is important that surgical performance assessment include variables beyond the speed of task completion, as speed in itself is not informative of the quality of the performance $[6,29]$.

On its own, Underground has very limited built-in capabilities to measure performance. This lack of reliable performance metrics is one of its biggest limitations at present [20,24]. In the course of conducting our pilot study, it became clear that the game-supplied variables (number of robots saved and number of bonus items collected) did not discriminate between laparoscopic experience, as nearly all pilot study participants achieved the maximum score regardless of laparoscopic experience. Well-developed in-game performance metrics would 
improve the usefulness of Underground for basic laparoscopic skills training.

Future developments in the area of serious gaming for laparoscopic skills development would benefit from a more formal approach to the development of in-game metrics. Delphi method-based rounds that include students, experts from the video game industry, content experts (eg, surgeons), and educational psychologists may help unlock the full potential of serious gaming by combining insights from each of these complementary professional groups. With regard to Underground specifically, continued support of its developers could overcome the current lack of informative parameters in the game by providing a game update via a patch, as is commonplace for contemporary video games. The low cost and small form factor of Underground facilitate its installation in non-skills lab settings such as residents' homes or offices. This flexibility may increase residents' training volumes.

Given that Underground is a game-based educational tool, and given that gaming has increasingly become an integral part of residents' and surgeons' daily lives [30], we additionally assessed the effect of the subjects' prior video game experience on their Underground gaming performance. A greater amount of prior gaming experience was found to be associated with faster performance in the novice and intermediate groups. These results are consistent with previous studies, where video game experience has been shown to improve baseline performance on simulators [31,32]. Interestingly, prior video game experience did not result in better Underground performance within the expert group. This finding can be explained by a generational difference in the subject groups, since the novices and intermediates generally had more video game experience than the experts. Alternatively, it is possible that experts' video game experience made a negligible contribution to their performance compared with the impact of their professional experience. The literature is divided as to whether video game experience positively impacts operating room performance, with some studies finding a positive effect and others finding no impact [30,33-38].

Adopting Underground in our training curricula corresponds well with the current interest in multimodality training, which in the context of surgical training refers to the use of different simulations to train specific surgical skills [39]. Several studies have shown that junior residents particularly benefit from multimodality training for mastering basic laparoscopic skills [39-41]. This training provides the trainee with a fresh perspective each time a new modality is used, which enhances their learning [39]. It would be beneficial to residents to broaden this approach even further by including games such as Touch Surgery for training the procedural aspects of surgical procedures in addition to basic psychomotor skills [42-45].

\section{Limitations}

Our experience groups comprised different gender ratios, reflecting the increase in the number of women enrolling in medical school. As a result, our novice group had a greater proportion of female participants than the intermediate and expert groups. However, gender only impacted the results in the novice group. Since female participants in this group also showed a difference in gaming experience, we were not able to independently assess the effect of gender. Given the lack of impact of gender on the other 2 groups, we think the gender effects in the novice group are caused by differences in gaming experience rather than gender differences per se.

Methods for validity testing are changing. Currently, 2 main frameworks are used in the literature: the classic validity framework, which includes validity sources such as face, content, construct and concurrent validity, and the modern framework proposed by Messick et al [46], which is a unified model in which different sources of validity are explored. In our studies of serious gaming, we opted to use the older framework so that our results would be comparable with those of other literature reports in this area (eg, Jalink et al [18]). This provides a better benchmark regarding the potential of Underground as a serious game for laparoscopic training. In the more current Messick framework, our study would support "relations to other variables" as sources of validity $[46,47]$.

\section{Future Research}

Understanding which specific aspects of the serious game Underground are responsible for laparoscopic skills transfer would aid its adoption in the surgical skills curriculum $[48,49]$. It is possible that the specialized laparoscopic gaming interface, compared to the original Wii U GamePad, is a critical component influencing laparoscopic skills transfer; this effect should be investigated further. In addition, if skill transfer to the operating room can be established, the potential value of serious games such as Underground will be heightened both for future laparoscopic skills training and for use as a preoperative warmup tool [50].

\section{Conclusion}

This study establishes construct validity for the laparoscopic serious game Underground. Serious gaming may aid laparoscopic skill development. Gaming experience had an independent, positive effect on Underground performance compared to laparoscopic experience. The in-game performance metrics were not suitable for statistical evaluation. To unlock the full potential of serious gaming for training, a more formal approach to the development of performance metrics is needed.

\section{Conflicts of Interest}

None declared.

\section{References}


1. Aggarwal R, Ward J, Balasundaram I, Sains P, Athanasiou T, Darzi A. Proving the effectiveness of virtual reality simulation for training in laparoscopic surgery. Ann Surg 2007 Nov;246(5):771-779. [doi: 10.1097/SLA.0b013e3180f61b09] [Medline: $\underline{17968168]}$

2. Verdaasdonk EGG, Dankelman J, Schijven MP, Lange JF, Wentink M, Stassen LPS. Serious gaming and voluntary laparoscopic skills training: a multicenter study. Minim Invasive Ther Allied Technol 2009 Aug;18(4):232-238. [doi: 10.1080/13645700903054046] [Medline: 19575329]

3. Burden C, Appleyard T, Angouri J, Draycott TJ, McDermott L, Fox R. Implementation of laparoscopic virtual-reality simulation training in gynaecology: a mixed-methods design. Eur J Obstet Gynecol Reprod Biol 2013 Oct;170(2):474-479. [doi: 10.1016/j.ejogrb.2013.07.003] [Medline: 23932183]

4. Gostlow H, Marlow N, Babidge W, Maddern G. Systematic Review of Voluntary Participation in Simulation-Based Laparoscopic Skills Training: Motivators and Barriers for Surgical Trainee Attendance. J Surg Educ 2017;74(2):306-318. [doi: 10.1016/j.jsurg.2016.10.007] [Medline: 27836238]

5. Vanderbilt AA, Grover AC, Pastis NJ, Feldman M, Granados DD, Murithi LK, et al. Randomized controlled trials: a systematic review of laparoscopic surgery and simulation-based training. Glob J Health Sci 2014 Dec 12;7(2):310-327 [FREE Full text] [doi: 10.5539/gjhs.v7n2p310] [Medline: 25716408]

6. Dawe SR, Pena GN, Windsor JA, Broeders JAJL, Cregan PC, Hewett PJ, et al. Systematic review of skills transfer after surgical simulation-based training. Br J Surg 2014 Aug;101(9):1063-1076. [doi: 10.1002/bjs.9482] [Medline: 24827930]

7. Graafland M, Ten Cate O, van Seventer J, Schraagen JMC, Schijven MP. Mapping the Demand for Serious Games in Postgraduate Medical Education Using the Entrustable Professional Activities Framework. Games Health J 2015 Oct;4(5):381-386. [doi: 10.1089/g4h.2014.0129] [Medline: 26287929]

8. Bergeron B. Developing Serious Games (game Development Series). 73 Tv Pl, Needham Heights, MA 02494, USA: Charles River Media; Jan 10, 2006:480.

9. Sharp L. Stealth Learning: Unexpected Learning Opportunities Through Games. JIR 2012 Jan 25;1:42-48. [doi: 10.9743/jir.2013.6]

10. Michael D, Chen S. Serious Games: Games That Educate, Train, and Inform. Boston, USA: Course Technology PTR; 2006:312.

11. Susi T. University of Skövde, Sweden: School of Humanities and Informatics. 2007. Serious Games - An Overview URL: https://www.researchgate.net/publication/220017759_Serious_Games_-_An_Overview [accessed 2020-04-20]

12. Foletto AA, Cordeiro d'Ornellas M, Cervi Prado AL. Serious Games for Parkinson's Disease Fine Motor Skills Rehabilitation Using Natural Interfaces. Stud Health Technol Inform 2017;245:74-78. [Medline: 29295055]

13. Macedo A, Prada R, Santos P, Ferreira J, Domingos J. Serious Game for Motion Disorders Rehabilitation of Parkinson's Disease Patients. URL: https://gaips.inesc-id.pt/component/gaips/publications/showPublicationPdf?pid=444\&format=raw [accessed 2020-04-18]

14. Pompeu JE, Mendes FADS, Silva KGD, Lobo AM, Oliveira TDP, Zomignani AP, et al. Effect of Nintendo Wii ${ }^{\mathrm{TM}}$-based motor and cognitive training on activities of daily living in patients with Parkinson's disease: a randomised clinical trial. Physiotherapy 2012 Sep;98(3):196-204. [doi: 10.1016/j.physio.2012.06.004] [Medline: 22898575]

15. Mautone T, Spiker V, Karp M. Using Serious Game Technology to Improve Aircrew Training. 2008 Presented at: Interservice/Industry Training, Simulation, and Education Conference (I/ITSEC); 2008; Orlando, Florida.

16. Goris J, Jalink MB, Ten Cate Hoedemaker HO. Training basic laparoscopic skills using a custom-made video game. Perspect Med Educ 2014 Sep;3(4):314-318 [FREE Full text] [doi: 10.1007/s40037-013-0106-8] [Medline: 24408736]

17. IJgosse WM, van Goor H, Luursema J. Saving robots improves laparoscopic performance: transfer of skills from a serious game to a virtual reality simulator. Surg Endosc 2018 Jul;32(7):3192-3199. [doi: 10.1007/s00464-018-6036-0] [Medline: 29349543]

18. Jalink MB, Goris J, Heineman E, Pierie JPEN, ten Cate Hoedemaker HO. Construct and concurrent validity of a Nintendo Wii video game made for training basic laparoscopic skills. Surg Endosc 2014 Feb;28(2):537-542. [doi: 10.1007/s00464-013-3199-6] [Medline: 24061627]

19. Risucci DA. Visual spatial perception and surgical competence. Am J Surg 2002 Sep;184(3):291-295. [doi: 10.1016/s0002-9610(02)00937-6] [Medline: 12354602]

20. Graafland M, Vollebergh MF, Lagarde SM, van Haperen M, Bemelman WA, Schijven MP. A serious game can be a valid method to train clinical decision-making in surgery. World J Surg 2014 Dec;38(12):3056-3062. [doi:

10.1007/s00268-014-2743-4] [Medline: 25159118]

21. Onderzoek CCM. 2019 15-11-2019; URL: https://tinyurl.com/ydy2rqtu [accessed 2020-04-18]

22. van Dongen KW, Tournoij E, van der Zee DC, Schijven MP, Broeders IAMJ. Construct validity of the LapSim: can the LapSim virtual reality simulator distinguish between novices and experts? Surg Endosc 2007 Aug;21(8):1413-1417. [doi: 10.1007/s00464-006-9188-2] [Medline: 17294307 ]

23. Nintendo Wii Support. 2018. Cursor is off-centre, jerky, erratic, disappears, etc URL: https://tinyurl.com/ycv6bztl [accessed 2020-04-18] 
24. Overtoom EM, Jansen F, van Santbrink EJP, Schraffordt Koops SE, Veersema S, Schreuder HWR. Training in Basic Laparoscopic Surgical Skills: Residents Opinion of the New Nintendo Wii-U Laparoscopic Simulator. J Surg Educ 2017;74(2):352-359. [doi: 10.1016/j.jsurg.2016.10.004] [Medline: 27789193]

25. Jalink MB, Goris J, Heineman E, Pierie JEN, Ten Cate Hoedemaker HO. Face validity of a Wii U video game for training basic laparoscopic skills. Am J Surg 2015 Jun;209(6):1102-1106. [doi: 10.1016/j.amjsurg.2014.09.034] [Medline: 25686513]

26. Harbin AC, Nadhan KS, Mooney JH, Yu D, Kaplan J, McGinley-Hence N, et al. Prior video game utilization is associated with improved performance on a robotic skills simulator. J Robot Surg 2017 Sep;11(3):317-324. [doi: 10.1007/s11701-016-0657-x] [Medline: 27853947]

27. Faul F, Erdfelder E, Buchner A, Lang A. Statistical power analyses using G*Power 3.1: tests for correlation and regression analyses. Behav Res Methods 2009 Nov;41(4):1149-1160. [doi: 10.3758/BRM.41.4.1149] [Medline: 19897823]

28. Field A, Andy. Discovering Statistics using IBM SPSS Statistics. In: Discovering Statistics Using Ibm Spss Statistics, 4th Edition. Thousand Oaks, California: Sage Publications Ltd; 2013:952.

29. Cotin S, Stylopoulos N, Ottensmeyer M, Neumann P, Rattner D, Dawson S. Metrics for Laparoscopic Skills Trainers: The Weakest Link!. 2002 Oct 10 Presented at: International Conference on Medical Image Computing and Computer-Assisted Intervention; September 25-28, 2002; Tokyo, Japan.

30. Rosser JC, Lynch PJ, Cuddihy L, Gentile DA, Klonsky J, Merrell R. The impact of video games on training surgeons in the 21st century. Arch Surg 2007 Feb;142(2):181-6; discusssion 186. [doi: 10.1001/archsurg.142.2.181] [Medline: 17309970]

31. Enochsson L, Isaksson B, Tour R, Kjellin A, Hedman L, Wredmark T, et al. Visuospatial skills and computer game experience influence the performance of virtual endoscopy. J Gastrointest Surg 2004 Nov;8(7):876-82; discussion 882. [doi: 10.1016/j.gassur.2004.06.015] [Medline: 15531242]

32. Grantcharov TP, Bardram L, Funch-Jensen P, Rosenberg J. Impact of hand dominance, gender, and experience with computer games on performance in virtual reality laparoscopy. Surg Endosc 2003 Jul;17(7):1082-1085. [doi:

10.1007/s00464-002-9176-0] [Medline: 12728373]

33. Boyle E, Kennedy A, Traynor O, Hill ADK. Training surgical skills using nonsurgical tasks--can Nintendo Wii ${ }^{\text {TM }}$ improve surgical performance? J Surg Educ 2011;68(2):148-154. [doi: 10.1016/j.jsurg.2010.11.005] [Medline: 21338974]

34. Plerhoples TA, Zak Y, Hernandez-Boussard T, Lau J. Another use of the mobile device: warm-up for laparoscopic surgery. J Surg Res 2011 Oct;170(2):185-188. [doi: 10.1016/j.jss.2011.03.015] [Medline: 21529831]

35. van Dongen KW, Verleisdonk EMM, Schijven MP, Broeders IAMJ. Will the Playstation generation become better endoscopic surgeons? Surg Endosc 2011 Jul;25(7):2275-2280 [FREE Full text] [doi: 10.1007/s00464-010-1548-2] [Medline: 21416186]

36. Rosenberg BH, Landsittel D, Averch TD. Can video games be used to predict or improve laparoscopic skills? J Endourol 2005 Apr;19(3):372-376. [doi: 10.1089/end.2005.19.372] [Medline: 15865530]

37. Schlickum MK, Hedman L, Enochsson L, Kjellin A, Felländer-Tsai L. Systematic video game training in surgical novices improves performance in virtual reality endoscopic surgical simulators: a prospective randomized study. World J Surg 2009 Nov;33(11):2360-2367. [doi: 10.1007/s00268-009-0151-y] [Medline: 19649553]

38. Madan AK, Frantzides CT, Park WC, Tebbit CL, Kumari NVA, O'Leary PJ. Predicting baseline laparoscopic surgery skills. Surg Endosc 2005 Jan;19(1):101-104. [doi: 10.1007/s00464-004-8123-7] [Medline: 15531975]

39. Kowalewski KF, Garrow CR, Proctor T, Preukschas AA, Friedrich M, Müller PC, et al. LapTrain: multi-modality training curriculum for laparoscopic cholecystectomy-results of a randomized controlled trial. Surg Endosc 2018 Feb 12. [doi: 10.1007/s00464-018-6110-7] [Medline: 29435758]

40. Zendejas B, Brydges R, Hamstra SJ, Cook DA. State of the evidence on simulation-based training for laparoscopic surgery: a systematic review. Ann Surg 2013 Apr;257(4):586-593. [doi: 10.1097/SLA.0b013e318288c40b] [Medline: 23407298]

41. Chandra V, Nehra D, Parent R, Woo R, Reyes R, Hernandez-Boussard T, et al. A comparison of laparoscopic and robotic assisted suturing performance by experts and novices. Surgery 2010 Jun;147(6):830-839. [doi: 10.1016/j.surg.2009.11.002] [Medline: 20045162]

42. Haubruck P, Nickel F, Ober J, Walker T, Bergdolt C, Friedrich M, et al. Evaluation of App-Based Serious Gaming as a Training Method in Teaching Chest Tube Insertion to Medical Students: Randomized Controlled Trial. J Med Internet Res 2018 Dec 21;20(5):e195 [FREE Full text] [doi: 10.2196/jmir.9956] [Medline: 29784634]

43. Kowalewski K, Hendrie JD, Schmidt MW, Proctor T, Paul S, Garrow CR, et al. Validation of the mobile serious game application Touch Surgery ${ }^{\mathrm{TM}}$ for cognitive training and assessment of laparoscopic cholecystectomy. Surg Endosc 2017 Oct;31(10):4058-4066. [doi: 10.1007/s00464-017-5452-x] [Medline: 28281111]

44. Sugand K, Mawkin M, Gupte C. Validating Touch Surgery ${ }^{\mathrm{TM}}$ : A cognitive task simulation and rehearsal app for intramedullary femoral nailing. Injury 2015 Nov;46(11):2212-2216. [doi: 10.1016/j.injury.2015.05.013] [Medline: 26094504]

45. Paro JAM, Luan A, Lee GK. Validation of a Cognitive Task Simulation and Rehearsal Tool for Open Carpal Tunnel Release. Arch Plast Surg 2017 May;44(3):223-227 [FREE Full text] [doi: 10.5999/aps.2017.44.3.223] [Medline: 28573097]

46. Borgersen NJ, Naur TMH, Sørensen SMD, Bjerrum F, Konge L, Subhi Y, et al. Gathering Validity Evidence for Surgical Simulation: A Systematic Review. Ann Surg 2018 Jun;267(6):1063-1068. [doi: 10.1097/SLA.0000000000002652] [Medline: 29303808]

47. Cook DA, Hatala R. Validation of educational assessments: a primer for simulation and beyond. Adv Simul (Lond) 2016;1:31 [FREE Full text] [doi: 10.1186/s41077-016-0033-y] [Medline: 29450000] 
48. Rosser JC, Liu X, Jacobs C, Choi KM, Jalink MB, Ten Cate Hoedemaker HO. Impact of Super Monkey Ball and Underground video games on basic and advanced laparoscopic skill training. Surg Endosc 2017 Apr;31(4):1544-1549. [doi: 10.1007/s00464-016-5059-7] [Medline: 27631319]

49. Harrington CM, Chaitanya V, Dicker P, Traynor O, Kavanagh DO. Playing to your skills: a randomised controlled trial evaluating a dedicated video game for minimally invasive surgery. Surg Endosc 2018 Feb 14;32(9):3813-3821. [doi: 10.1007/s00464-018-6107-2]

50. Jalink MB, Heineman E, Pierie JPEN, ten Cate Hoedemaker HO. The effect of a preoperative warm-up with a custom-made Nintendo video game on the performance of laparoscopic surgeons. Surg Endosc 2015 Aug;29(8):2284-2290. [doi: 10.1007/s00464-014-3943-6] [Medline: 25361658]

\section{Abbreviations \\ ANCOVA: analysis of covariance}

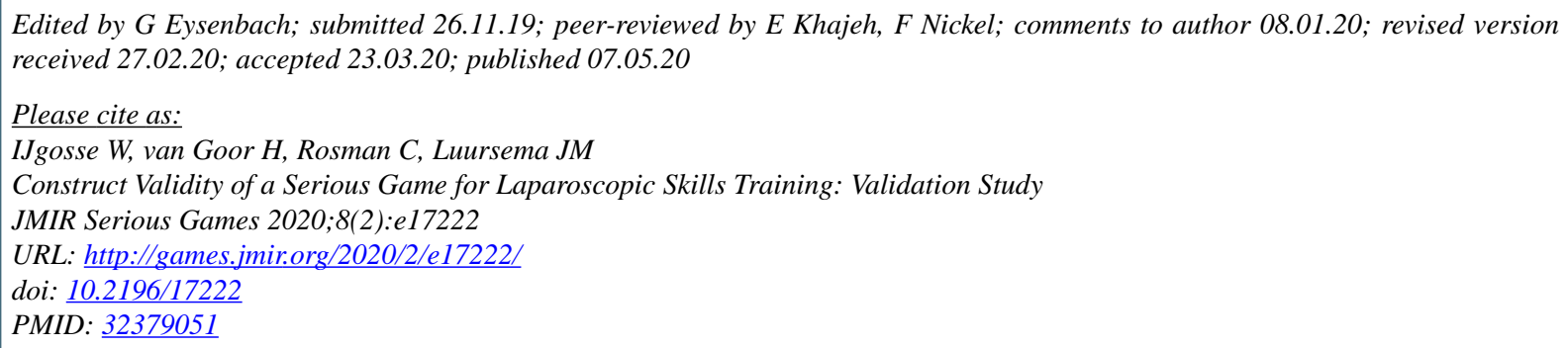

(CWouter IJgosse, Harry van Goor, Camiel Rosman, Jan-Maarten Luursema. Originally published in JMIR Serious Games (http://games.jmir.org), 07.05.2020. This is an open-access article distributed under the terms of the Creative Commons Attribution License (https://creativecommons.org/licenses/by/4.0/), which permits unrestricted use, distribution, and reproduction in any medium, provided the original work, first published in JMIR Serious Games, is properly cited. The complete bibliographic information, a link to the original publication on http://games.jmir.org, as well as this copyright and license information must be included. 